\title{
THE CROSSABILITIES OF WHEAT VARIETIES WITH HORDEUM BULBOSUM
}

\author{
J. W. SNAPE, V. CHAPMAN, J. MOSS, C. E. BLANCHARD and T. E. MILLER \\ Plant Breeding Institute, Maris Lane, Trumpington, Cambridge CB2 2LQ
}

Received 15.xii.78

\begin{abstract}
SUMmary
Two experiments to investigate the crossabilities of varieties of bread wheat, Triticum aestivum, with Hordeum bulbosum are described. In the first a range of varieties having low and high crossability with rye, Secale cereale, were used. It was found that a strong positive correlation between the crossabilities of wheat varieties with $H$. bulbosum and with rye exists.

In the second experiment the genetics of crossability was investigated using chromosome substitution lines of the non-crossable variety, Hope, into the crossable variety Chinese Spring. Two chromosomes, namely 5A and 5B of Hope, were found to reduce markedly the crossability of Chinese Spring. These chromosomes were those identified by Riley and Chapman (1967) as being responsible for the crossability of Chinese Spring with rye, reinforcing the conclusion that the crossability of wheat with both species is governed, at least in part, by the same genetic system. However, other chromosomes were also shown to affect the crossability of Chinese Spring, although to a much lesser extent. The use of this interspecific cross to produce wheat dihaploid lines for breeding purposes is discussed.
\end{abstract}

\section{INTRODUCTION}

THE progenies of the interspecific cross between Hordeum bulbosum $(2 n=$ $2 x=14)$ and Hordeum vulgare $(2 n=2 x=14)$ are usually haploid $H$. vulgare plants because of the elimination of the $H$. bulbosum chromosomes during embryo development (Kasha and Kao, 1970; Kasha and Subrahmanyam, 1973). By crossing $\mathrm{F}_{1}$ hybrids between different $H$. vulgare cultivars with H. bulbosum, and treating the resulting progeny with colchicine, dihaploid lines can be obtained which are the products of recombination in the $F_{1}$ and combine the parental characteristics in homozygous lines. The high frequencies of such dihaploid lines now obtainable with this technique, have led to its incorporation into barley breeding programmes in many countries. This technique has the advantage over conventional pedigree breeding methods that genetic uniformity is achieved in one generation, only a short time after the initial hybridisation so that selection and multiplication are more easily facilitated (Reinbergs et al., 1976; Park et al., 1976).

The discovery by Barclay (1975) that the interspecific cross between Triticum aestivum $(2 n=6 x=42)$ variety Chinese Spring and both diploid $(2 n=2 x=14)$ and tetraploid $(2 n=4 x=28)$ Hordeum bulbosum resulted in the production of haploid $T$. aestivum plants raised hopes that the dihaploid technique could also be exploited in wheat breeding programmes. Barclay obtained a frequency of 13.7 per cent grains set with diploid $H$. bulbosum and a frequency of 43.7 per cent grains set with tetraploid $H$. bulbosum. The latter frequency, which although only half the frequency in $H$. vulgare 
crosses with diploid $H$. bulbosum, is still sufficient to enable the technique to be a useful breeding procedure.

However before the technique can be exploited in wheat it is necessary to test if other wheat varieties will produce haploids in crosses with $H$. bulbosum and whether these frequencies are sufficiently high to make dihaploid production a feasible breeding procedure with modern high yielding cultivars. The results of Barclay (1976) with other varieties were not encouraging. He found that no grains were set in crosses of the varieties Hope, Cappelle-Desprez and Vilmorin 27 with tetraploid H. bulbosum and this difference from Chinese Spring indicates that there is genetic variation for crossability between wheat varieties.

The present investigations were initiated to examine a wider range of varieties for their crossability with $H$. bulbosum and also to elucidate the genetical control of the crossability of Chinese Spring.

The varieties were chosen to form a sample having known high and low crossability with rye, Secale cereale $(2 n=2 x=14)$. This criterion was used because the results of Barclay (loc. cit.) suggest that there is a relationship between the crossability of wheat with both rye and $H$. bulbosum since Chinese Spring has a high crossability, and the other varieties used by Barclay a low crossability, with both species.

\section{Materials AND methods}

(i) Experiment 1: The crossabilities of different varieties of wheat with $\mathrm{H}$. bulbosum and rye

The wheat varieties investigated are shown in table 1 . These comprise a sample of European winter and spring wheats chosen to represent varieties of diverse parentages, and reported as having low crossability with rye, and a sample of mainly Australian varieties reported as having a high crossability with rye. These latter varieties were obtained from $\mathrm{Dr} \mathrm{N}$. Darvey of the Plant Breeding Institute, University of Sydney, Australia.

The $H$. bulbosum clones used in the investigations were grown from seed obtained from Dr D. B. H. Sparrow of the Waite Institute, Adelaide, Australia, and comprised a mixture of tetraploid clones of Mediterranean origin. Individual $H$. bulbosum plants for the experiment were obtained by cloning from single bulbs.

All hybridisations with rye were carried out using the variety Petkus Spring.

Plants of all genotypes used in the investigations were grown in an unheated glasshouse during the summer. All hybridisations with $H$. bulbosum and rye were carried out with wheat as the female parent. Immature ears were emasculated after first removing apical and basal spikelets and all except the two outermost florets of the other spikelets to achieve similar stages of maturity throughout the ear. Mature stigmas were pollinated with freshly collected $H$. bulbosum or rye pollen. Because of variations in flowering times, crosses of different varieties were made at different times during the crossing season and all five authors were involved in the crossing.

At 15 to 18 days after pollination, ears were scored for numbers of grains set. After about 15 days the grains produced from the $H$. bulbosum crosses would begin to abort because of lack of endosperm development so that embryo culture was necessary for further development. Using an aseptic 
TABLE I

Crossabilities of varieties with $\mathrm{H}$. bulbosum and rye

\begin{tabular}{|c|c|c|c|c|c|}
\hline \multirow[b]{3}{*}{ Variety } & \multirow[b]{3}{*}{ Description } & \multicolumn{4}{|c|}{ Pollinator } \\
\hline & & \multicolumn{2}{|c|}{ H. bulbosum } & \multicolumn{2}{|c|}{ Rye } \\
\hline & & $\begin{array}{l}\text { No. florets } \\
\text { pollinated }\end{array}$ & $\%$ set & $\begin{array}{l}\text { No. florets } \\
\text { pollinated }\end{array}$ & $\%$ set \\
\hline Holdfast & English winter wheat & 126 & $0 \cdot 0$ & 52 & 3.8 \\
\hline Cappelle-Desprez & French winter wheat & 58 & $0 \cdot 0$ & 56 & 1.8 \\
\hline Maris Widgeon & English winter wheat & 57 & $0 \cdot 0$ & 22 & 0.0 \\
\hline Rothwcll Perdix & English winter wheat & 66 & $0 \cdot 0$ & 66 & 1.5 \\
\hline Sirius & German spring wheat & 59 & $0 \cdot 0$ & - & - \\
\hline Highbury & English spring wheat & 196 & $0 \cdot 0$ & 160 & 0.0 \\
\hline Sicco & Dutch spring wheat & 200 & $0 \cdot 0$ & 120 & $3 \cdot 0$ \\
\hline 155612 & PBI spring selection & 192 & $0 \cdot 0$ & 90 & 0.0 \\
\hline Timgalen & Australian spring wheat & 484 & 6.0 & 176 & $23 \cdot 0$ \\
\hline Songlen & Australian spring wheat & 166 & $4 \cdot 0$ & 68 & $25 \cdot 0$ \\
\hline Sun $21 \mathrm{~A}$ & Australian spring wheat & 140 & $0 \cdot 0$ & 99 & 4.0 \\
\hline Timson & Australian spring wheat & 141 & $0 \cdot 0$ & 70 & $23 \cdot 0$ \\
\hline Wren & Australian spring wheat & 434 & $1 \cdot 6$ & 172 & $66 \cdot 0$ \\
\hline Gamut & Australian spring wheat & 90 & $10 \cdot 1$ & 62 & $58 \cdot 0$ \\
\hline TH 3929 & Chinese winter wheat & 138 & $35 \cdot 5$ & 85 & $88 \cdot 2$ \\
\hline Sonora 64 & CIMMYT spring wheat & 186 & 0.0 & 45 & 0.0 \\
\hline
\end{tabular}

technique a sample of embryos from all crossable varieties were excised and placed on orchid agar in $20 \mathrm{~mm}$ glass test-tubes. The embryos were then germinated in the dark in an incubator at $20^{\circ} \mathrm{C}$. When roots and a coleoptile were visible the tubes were transferred to a lighted growth cabinet at $25^{\circ} \mathrm{C}$ with light intensity approximately 5000 lux to allow chlorophyll development and further growth. When plants had well developed leaves and roots they were transferred from agar into soil and grown to maturity in the glasshouse.

(ii) Experiment 2: Genetics of the crossability of Chinese Spring with $\mathrm{H}$. bulbosum

To identify the chromosomes carrying the genes responsible for the crossability of Chinese Spring with $H$. bulbosum the complete set of single chromosome substitution lines, in which the chromosomes of the noncrossable variety Hope had replaced their homologues in Chinese Spring, were used. These were developed by Dr E. R. Sears at the University of Missouri, U.S.A., and had been used in previous investigations of the crossability of Chinese Spring with rye by Riley and Chapman (1967). These lines were grown together with plants of the two parental varieties. The same $H$. bulbosum clones as in Experiment 1 were used for pollination. The procedures described in Experiment 1 were used except that no crosses with rye were carried out.

\section{Results}

\section{(i) Experiment 1}

The crossabilities of the varieties hybridised with rye and $H$. bulbosum are shown in table 1. These data represent the results of crossing different ears of each variety and for presentation the data have been summed over 
ears and the crossabilities expressed as the percentage number of grains set to the total number of florets pollinated.

Considering first the pollinations with $H$. bulbosum, clearly none of the European wheat varieties were crossable as no grains were set in almost a thousand florets pollinated. However, four of the six Australian varieties were crossable even though the frequency was low. The variety TH 3929, however, was highly crossable and the frequency was comparable with that reported by Barclay for Chinese Spring. Viable plants of all these varieties were obtained by embryo culture. These were morphologically similar to the wheat parents and in all cases were sterile haploids.

Turning to the pollinations with rye, grains were obtained with all varieties except Maris Widgeon, Highbury, 155612 and Sonora 64. However, none of the European varieties was particularly crossable with rye and only one or two grains per ear were obtained. However, all the Australian varieties apart from Sun $21 \mathrm{~A}$, set grains readily with rye and the very high frequency obtained with TH 3929 was comparable with the frequency usually obtained in intra-varietal pollinations with wheat.

From table 1 we can also see that there is a clear relationship between the crossabilities of the varieties with $H$. bulbosum and rye. Considering all varieties, there was a positive correlation of $0.79(\mathrm{P}<0.01)$ between the crossabilities and considering only those five varieties that were crossable with both species a correlation of 0.70 was obtained.

We can examine statistically the variation in crossabilities of the five varieties that were crossable with both species by means of contingency $\chi^{2}$ analysis (Crawford-Sidebotham, 1970). Table 2 shows the significance of variation between varieties and pollinators and the interaction between them. As is obvious from table 1 highly significant differences are obtained between pollinators and varieties. However, the interaction between these main effects is also significant. This suggests that although a strong correlation between the crossabilities was exhibited there may also be a degree of independent genetical control since some varieties, for example Wren, did not cross as readily with $H$. bulbosum as their crossability with rye would predict.

TABLE 2

Significance of variation in crossabilities of varieties crossable with $\mathrm{H}$. bulbosum and rye

$\begin{array}{lccc}\text { Item } & \text { df } & \chi^{2} & \text { P } \\ \text { Pollinators } & 1 & 435.5 & <0.001 \\ \text { Varieties } & 4 & 233.0 & <0.001 \\ \text { Pollinators } \times \text { Varieties } & 4 & 132.9 & <0.001\end{array}$

However, this variation could also have been influenced by environmental effects. The varieties were pollinated at different times and by different workers and the changes in the glasshouse environment due to external weather conditions and the idiosyncrasies of technique of different workers will have contributed to the variation.

(ii) Experiment 2

The results of crossing Hope and Chinese Spring and the complete set of 21 substitution lines of Hope chromosomes into Chinese Spring with 
H. bulbosum are shown in table 3. Here, the data have again been summed over replicate ears and the percentage crossability expressed as the proportion of grains set to the total number of florets pollinated. Also shown is the probability of difference between each of the substitution lines and Chinese Spring. This was tested by transforming the data for individual ears to angles and carrying out $t$-tests between the mean of each line and the mean of Chinese Spring, using as error the variation between ears within lines.

Looking firstly at the data for the parental lines, Hope was non-crossable whereas, as expected, Chinese Spring was crossable. However, the frequency with Chinese Spring was much lower than that obtained by Barclay. This was possibly due to unfavourable environmental conditions in the glasshouse when Chinese Spring was pollinated since embryo development in Chinese Spring $\times H$. bulbosum progeny is particularly sensitive to environmental conditions (Snape and Blanchard, unpublished). Turning to the substitution lines, surprisingly, eight chromosomes of Hope, namely $1 \mathrm{~B}, 1 \mathrm{D}, 2 \mathrm{D}, 3 \mathrm{~A}, 3 \mathrm{D}$, $4 \mathrm{~A}, 4 \mathrm{~B}$ and $6 \mathrm{D}$ had significantly higher crossabilities than Chinese Spring and thus these chromosomes appear to promote crossability. This result is possibly due to the lower than expected frequency of Chinese Spring and none of these lines is significantly different from the frequency obtained by Barclay.

Substitution lines of chromosomes 5A and 5B had a significantly lower crossability than Chinese Spring and all chromosomes of this homoeologous group reduced crossability. In the case of $5 \mathrm{~B}$ no grains were obtained so

TABLE 3

Crossability of Hope/Chinese Spring substitution lines with $\mathrm{H}$. bulbosum

\begin{tabular}{|c|c|c|c|}
\hline Line & $\begin{array}{l}\text { No. florets } \\
\text { pollinated }\end{array}$ & $\%$ crossability & $\begin{array}{l}\text { Probability } \\
\text { of difference } \\
\text { from CS }\end{array}$ \\
\hline Chinese Spring (CS) & 302 & $17 \cdot 6$ & - \\
\hline Hope & 149 & $0 \cdot 0$ & $* * *$ \\
\hline Chinese Spring (Hope IA) & 85 & $18 \cdot 8$ & n.s. \\
\hline Chinese Spring (Hope IB) & 52 & $36 \cdot 5$ & $*$ \\
\hline Chinese Spring (Hope ID) & 85 & $35 \cdot 3$ & $*$ \\
\hline Chinese Spring (Hope 2A) & 79 & $21 \cdot 5$ & n.s. \\
\hline Chinese Spring (Hope 2B) & 46 & $28 \cdot 3$ & n.s. \\
\hline Chinese Spring (Hope 2D) & 106 & $50 \cdot 0$ & $* * *$ \\
\hline Chinese Spring (Hope 3A) & 52 & $38 \cdot 5$ & $*$ \\
\hline Chinese Spring (Hope 3B) & 54 & $16 \cdot 7$ & n.s. \\
\hline Chinese Spring (Hope 3D) & 83 & $39 \cdot 8$ & $* *$ \\
\hline Chinese Spring (Hope 4A) & 52 & $46 \cdot 2$ & $* *$ \\
\hline Chinese Spring (Hope 4B) & 47 & $42 \cdot 6$ & $* *$ \\
\hline Chinese Spring (Hope 4D) & 85 & $30 \cdot 6$ & n.s. \\
\hline Chinese Spring (Hope 5A) & 122 & $4 \cdot 9$ & $* *$ \\
\hline Chinese Spring (Hope 5B) & 84 & $0 \cdot 0$ & $* * *$ \\
\hline Chinese Spring (Hope 5D) & 92 & $9 \cdot 8$ & n.s. \\
\hline Chinese Spring (Hope 6A) & 49 & $25 \cdot 6$ & n.s. \\
\hline Chinese Spring (Hope 6B) & 55 & $32 \cdot 7$ & n.s. \\
\hline Chinese Spring (Hope 6D) & 54 & $42 \cdot 6$ & $* *$ \\
\hline Chinese Spring (Hope 7A) & 58 & $31 \cdot 0$ & n.s. \\
\hline Chinese Spring (Hope 7B) & 52 & $13 \cdot 5$ & n.s. \\
\hline Chinese Spring (Hope 7D) & 54 & $20 \cdot 4$ & n.s. \\
\hline
\end{tabular}

Probability: $*=0.05-0.01, * *=0.01-0.001, * * *<0.001$. 
that this chromosome obviously has a major effect on the crossability of Chinese Spring. Chromosomes 5A and 5B of Hope were the chromosomes identified by Riley and Chapman (1967) as inhibiting the crossability with rye and chromosome $5 \mathrm{~B}$ was identified as carrying the gene $K r \mathrm{l}$ and chromosome $5 \mathrm{~A}, \mathrm{~K} r 2$. It seems likely therefore that the non-crossability of Hope with $H$. bulbosum is also controlled to a major extent by these loci, and this would also explain the relationship between the crossabilities of the varieties examined in Experiment 1. This hypothesis is further supported by the magnitude of the effects since Riley and Chapman found that with respect to reducing rye crossability $k r \mathrm{l}$ on Hope $5 \mathrm{~B}$ was more potent than $\kappa r 2$ on $5 \mathrm{~A}$ and this was also the case with crossability with $H$. bulbosum.

However, the difference in crossability between Hope and Chinese Spring was not due entirely to these two chromosomes and other chromosomes appear to have an effect. The effects of the different chromosomes can be separated statistically by analysing the variation between lines using the analysis of variance. This analysis was carried out by converting the data for percentage crossability of individual ears to angles and comparing the between-line variation with the variation between ears within lines. This should also provide a more meaningful comparison between lines than comparing each against Chinese Spring because of the low value of Chinese Spring in this experiment. Because chromosome 5B had zero crossability, however, and is obviously different from the rest, it has been removed from the analysis and the variation between the remaining 20 lines has been examined.

The analysis of variance of the data is shown in table 4 and there is a highly significant difference between the substitution lines with respect to their crossability with $H$. bulbosum. Partitioning this variation into the effect of $5 \mathrm{~A}$ and $5 \mathrm{D}$ versus the remaining lines, the effect of $5 \mathrm{~A}$ against $5 \mathrm{D}$, and the remaining line variation shows that a major component of the line variation is due to differences between the chromosomes of homoeologous group 5 and the remaining chromosomes. Further, there is no significant difference between $5 \mathrm{~A}$ and $5 \mathrm{D}$ so that although Hope 5D was not significantly different from Chinese Spring on the individual test it would still appear to have an effect. This chromosome also reduced the crossability of Chinese Spring with rye (Riley and Chapman, 1967) although, as here, the effect was not statistically significant. Over and above the effect of the chromosomes of homoeologous group 5, however, there is still significant residual variation. Whether this residual variation is caused by genetical differences between chromosomes or environmental differences at the time of pollination cannot

\section{TABLE 4}

Analysis of variance of substitution line data (converted to angles)

\begin{tabular}{lrrrr}
\multicolumn{1}{c}{ Item } & d.f. & SS & \multicolumn{1}{c}{ MS } & P \\
Between substitution lines & 19 & 5382.6 & 283.3 & $<0.001$ \\
5A and 5D v. rest & 1 & 2831.7 & 2831.7 & $<0.001$ \\
5A v. 5D & 1 & 93.6 & 93.6 & $>0.20$ \\
Residual line var & 17 & 2457.3 & 144.5 & 0.02 \\
Between ears within lines & 33 & 2057.6 & 62.4 & -
\end{tabular}


be ascertained from these data. However, as in Experiment 1, differences in environmental conditions were present and could have contributed to this variation.

\section{Discussion}

The present investigation has identified a number of wheat varieties which are crossable with $H$. bulbosum. All also have good crossability with rye and the strong positive relationship between rye and $H$. bulbosum crossability as well as the genetic analysis of the crossability of Chinese Spring suggests that the same genetic system is responsible for the crossabilities with both species. Lange and Wojciechowska (1976) have examined the growth of pollen grains of rye on stigmas of Hope and Chinese Spring (Hope 5B) substitution line and have shown that the poor crossability with rye is brought about by retardation and eventual inhibition of pollen tube growth at the style base and in the transmitting tissue of the ovary wall so that no pollen tubes reach the embryo sac. If the same genes are operating then the same mechanism is likely to be responsible for non-crossability with $H$. bulbosum. Preliminary evidence on the pollen growth of $H$. bulbosum pollen on stigmas of Chinese Spring (Hope 5B) plants (Chapman and Moss, unpublished) shows that $H$. bulbosum pollen germinates readily on the stigma and that pollen tubes grow down the style so that although histological examination of embryo sacs has not yet been carried out, it would seem likely that the same mechanism as in rye is operating.

None of the European wheats examined in the first experiment was crossable with $H$. bulbosum and these only had a poor crossability with rye. Riley and Chapman (1967) report that almost all wheats of European and western Asia origin have poor crossability with rye. If this is the case then the correlation shown in the present experiment between rye and $H$. bulbosum crossability will greatly restrict the use of this dihaploid technique in European breeding programmes. Unless a way can be found of overcoming the incompatibility, for example by the use of drug treatment (Bates, Campos, Rodriguez and Anderson, 1974), the technique will only be of use with the occasional variety having good crossability with rye.

If a breeding programme is based on varieties that are highly crossable with rye, as many Australian varieties appear to be, then there may be a place for the use of the $H$. bulbosum technique. However, the frequency of haploid plants produced needs to be greatly increased over that found in the present experiment if the technique is to be a practical proposition. This problem also occurred initially in the barley breeding programmes and improvements in technique may increase the frequencies of grains set, and of haploids derived from these. In fact, in the first experiment here, evidence from histological examination of ovules 5 days after pollination (Snape and Blanchard, unpublished) showed that the frequency of fertilisation was much higher than the number of developed grains scored at 15 days after pollination. In the varieties Songlen and Timgalen, for example, the proportions of fertilised ovules were 50 per cent and 37 per cent respectively compared to a scored grain set of 4 per cent and 6 per cent. Obviously a great number of embryos failed to develop, probably because of unfavourable environmental conditions, and identification of the important environmental variables should allow an increase in the frequency of grains set.

Nevertheless there are also genetic barriers to the number of grains set 
caused by genetic variation at the crossability loci. Clearly Chinese Spring and TH 3929 possess genes whose effects result in higher levels of grains set than Timgalen and the other Australian varieties. Thus identification of the allelic variation present and a detailed knowledge of the inheritance of crossability should also facilitate the use of the dihaploid technique in wheat. In addition it may also be possible to exploit genetic variation in $H$. bulbosum. In crosses of varieties of $H$. vulgare with different clones of diploid $H$. bulbosum it has been found that certain clones produce higher frequencies of grain set (Simpson, unpublished). It may thus be profitable to screen different clones of tetraploid H. bulbosum to try and identify strains of higher crossability.

Acknowledgments.-The assistance of Mr E. Simpson, Miss B. B. Parker and Mr S. M. Reader is gratefully acknowledged.

\section{REFERENGES}

BARGLAY, I. R. 1975. High frequencies of haploid production in wheat (Triticum aestivum) by chromosome elimination. Nature, 256, 410-411.

BARCLAY, I. R. 1976. A study of the genetics and mechanism of genome and chromosome loss in cereals. Ph.D. thesis, University of Cambridge.

bates, L. S., CAMpos, U. A., RODRiguez, R. R., AND ANDerson, R. G. 1974. Progress toward novel cereal grains. Cereal Sci. Today, 19, 283-286.

CRAWFORD-SIDEBotham, T. J. 1970. Differential susceptibility of species of slugs to metaldehyde bran and to methiocarb baits. Oecologia (Berl.), 5, 303-324.

KASHA, K. J., AND KAO, K. N. 1970. High frequency haploid production in barley (Hordeum vulgare L.). Nature, 225, 874-876.

KASHA, K. J., AND SUBRAHMANYAM, N. C. 1973. Selective chromosomal elimination during haploid formation in barley following interspecific hybridisation. Chromosoma, 42, 111-125.

LANGE, W., AND WOJCIECHOWSKA, B. 1976. The crossing of common wheat (Triticum aestivum L.) with cultivated rye (Secale cereale L.). I. Crossability, pollen grain germination and pollen tube growth. Euphytica, 25, 609-620.

PARK, s. J., WALSH, E. J., REINBERGS, E., SONG, L. s. P., AND KASHA, K. J. 1976. Field performance of doubled haploid barley lines in comparison with lines developed by the pedigree and single seed descent methods. Can. F. Plant Sci., 56, 467-474.

REINBERGS, E., PARK, S. J., AND SONG, L. S. P. 1976. Early identification of superior barley crosses by the doubled haploid technique. Z. Pfanzenzuchtg., 76, 215-224.

RILEY, R., AND ChapMan, v. 1967. The inheritance in wheat of crossability with rye. Genet. Res., Camb., 9, 259-267. 